\title{
Conserved domains and evolution of secreted phospholipases $\mathbf{A}_{2}$
}

\author{
Timo J. Nevalainen ${ }^{1}$, João C. R. Cardoso ${ }^{2}$ and Pentti T. Riikonen ${ }^{3}$ \\ 1 Department of Pathology, University of Turku and Turku University Hospital, Finland \\ 2 Comparative Molecular Endocrinology, Centre of Marine Sciences, Universidade do Algarve, Campus de Gambelas, Faro, Portugal \\ 3 Department of Information Technology, University of Turku, Finland
}

\author{
Keywords \\ conserved domains; eukaryotes; evolution; \\ prokaryotes; secreted $\mathrm{PLA} \mathrm{S}_{2}$

\section{Correspondence} \\ Timo J. Nevalainen, Department of \\ Pathology, University of Turku, \\ Kiinamyllynkatu 10, FIN-20520 Turku, \\ Finland \\ Fax: +358 23337456 \\ Tel: +358 23337500 \\ E-mail: timneva@utu.fi
}

(Received 1 September 2011, revised 8 December 2011, accepted 13 December 2011)

doi:10.1111/j.1742-4658.2011.08453.x
Secreted phospholipases $\mathrm{A}_{2}\left(\mathrm{sPLA}_{2} \mathrm{~s}\right)$ are lipolytic enzymes present in organisms ranging from prokaryotes to eukaryotes but their origin and emergence are poorly understood. We identified and compared the conserved domains of $333 \mathrm{sPLA}_{2} \mathrm{~s}$ and proposed a model for their evolution. The conserved domains were grouped into seven categories according to the in silico annotated conserved domain collections of 'cd00618: $\mathrm{PLA}_{2}$ like' and 'pfam00068: Phospholip_A2_1'. PLA 2 s containing the conserved domain cd04706 (plant-specific $\mathrm{PLA}_{2}$ ) are present in bacteria and plants. Metazoan $\mathrm{PLA}_{2} \mathrm{~S}$ of the group $(\mathrm{G}) \mathrm{I} / \mathrm{II} / \mathrm{V} / \mathrm{X} \mathrm{PLA}_{2}$ collection exclusively contain the conserved domain cd00125. GIII PLA ${ }_{2} \mathrm{~S}$ of both vertebrates and invertebrates contain the conserved domain cd04704 (bee venom-like $\mathrm{PLA}_{2}$ ), and mammalian GIII PLA $\mathrm{P}_{2}$ also contain the conserved domain cd04705 (similar to human GIII PLA 2 ). The $\mathrm{sPLA}_{2} \mathrm{~s}$ of bacteria, fungi and marine invertebrates contain the conserved domain pfam09056 (prokaryotic $\mathrm{PLA}_{2}$ ) that is the only conserved domain identified in fungal $\mathrm{sPLA}_{2} \mathrm{~s}$. Pfam06951 (GXII PLA ( $_{2}$ ) is present in bacteria and is widely distributed in eukaryotes. All conserved domains were present across mammalian sPLA $_{2} \mathrm{~s}$, with the exception of cd04706 and pfam09056. Notably, no $\mathrm{sPLA}_{2} \mathrm{~S}$ were found in Archaea. Phylogenetic analysis of sPLA 2 conserved domains reveals that two main clades, the cd- and the pfam-collection, exist, and that they have evolved via gene-duplication and gene-deletion events. These observations are consistent with the hypothesis that $\mathrm{sPLA}_{2} \mathrm{~S}$ in eukaryotes shared common origins with two types of bacterial $\mathrm{SPLA}_{2} \mathrm{~s}$, and their persistence during evolution may be related to their role in phospholipid metabolism, which is fundamental for survival.

\section{Introduction}

\section{Phospholipases $A_{2}$}

Phospholipases $\mathrm{A}_{2}\left(\mathrm{PLA}_{2} \mathrm{~s}\right.$; EC 3.1.1.4) are a group of lipolytic enzymes that hydrolyze the $s n-2$ bond of phospholipids, such as phosphatidylcholine and phosphatidylethanolamine, resulting in the release of fatty acid and lysophospholipid. They have been isolated from organisms ranging from bacteria to mammals and are suggested to have emerged early in evolution. In general, $\mathrm{PLA}_{2} \mathrm{~S}$ are classified into three broad categories: $\mathrm{Ca}^{2+}$-dependent secreted $\mathrm{PLA}_{2} \mathrm{~S} \quad\left(\mathrm{sPLA}_{2} \mathrm{~s}\right)$; $\mathrm{Ca}^{2+}$-dependent cytosolic $\mathrm{PLA}_{2} \mathrm{~S}$; and $\mathrm{Ca}^{2+}$-independent cytosolic $\mathrm{PLA}_{2} \mathrm{~S}$. Cytosolic PLA $2 \mathrm{~S}$ are known to play an important role in cellular signalling and

\section{Abbreviations}

EST, expressed sequence tag; G, group; ML, maximum likelihood; NJ, neighbour-joining; OtoC, N-terminal region of otoconin; OtoN, $\mathrm{N}$-terminal region of otoconin; $\mathrm{PLA}$, phospholipase $\mathrm{A}_{2}$; $S P L A_{2}$, secreted phospholipase $\mathrm{A}_{2}$. 
prostanoid metabolism [1,2]. Secreted $\mathrm{PLA}_{2} \mathrm{~S}$ are components of various body fluids, including blood plasma, pancreatic juice, tears, seminal fluid, and snake and other venoms, and they participate in diverse physiological and pathological functions, such as in the digestion of dietary phospholipids, in inflammatory reactions and in the defence against bacteria and other pathogens [1-7].

\section{Secreted PLA $\mathrm{P}_{2}$}

Secreted $\mathrm{PLA}_{2} \mathrm{~S}$ are the product of distinct genes and they have been classified, according to their molecular structure, into the following groups: IA, IB, IIA, IIB, IIC, IID, IIE, IIF, III, V, IX, X, XIA, XIB, XIIA, XIIB, XIII and XIV [1]. Evidence of structural similarity among group (G)I, GII, GV and GX members was taken to suggest that they may form a distinct GI/II/V/X PLA 2 collection [8]. The GXIV $\mathrm{PLA}_{2} \mathrm{~s}$ of bacteria and fungi differ in their primary structure and folding from the other $\mathrm{SPLA}_{2} \mathrm{~s}$ [1].

Secreted $\mathrm{PLA}_{2} \mathrm{~S}$ are small-molecular-mass proteins (14-18 kDa, 120-135 amino acid residues) that require the presence of $\mathrm{Ca}^{2+}$ at millimolar concentrations for their catalytic activity. They share a conserved 3D structure that is stabilized by five to eight disulfide bonds. The structure of the GI, GII and GX PLA $2 \mathrm{~S}$ consists of three $\alpha$-helices, a two-stranded $\beta$-sheet (the $\beta$-wing) and a conserved $\mathrm{Ca}^{2+}$-binding loop [9-13]. The conserved catalytic network of GIB and GIIA $\mathrm{PLA}_{2} \mathrm{~S}$ consists of hydrogen-bonded side-chains formed by histidine, which is localized in the long $\alpha$-helix 1, tyrosine and aspartic acid residues, as well as the hydrophobic wall that shields it [14]. The ${ } P A_{2} \mathrm{~s}$ of plants have a different $3 \mathrm{D}$ structure. In the GXIB PLA 2 of rice (Oryza sativa) the $\beta$-wing is absent and the $\mathrm{C}$-terminal $\alpha$-helix 3 has a different orientation [15]. The $\mathrm{SPLA}_{2} \mathrm{~S}$ of prokaryotes and fungi are characterized by a dominant $\alpha$-helical fold [16].

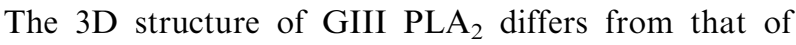
$\mathrm{GI} / \mathrm{II} / \mathrm{V} / \mathrm{X} \mathrm{PLA}_{2} \mathrm{~S}$ but they share identical motifs [17].

\section{Conserved domains of $\mathrm{SPLA}_{2} \mathrm{~s}$ and their evolution}

Functional motifs of $\mathrm{sPLA}_{2} \mathrm{~s}$ that are well conserved include the $\mathrm{Ca}^{2+}$-binding and catalytic sites, and the conserved cysteine residues and disulfide bond pattern [1,2]. In silico database annotations identified two conserved signature patterns: the 'PA2_HIS (PS0018, Phospholipase $\mathrm{A}_{2}$ histidine active site $\mathrm{C}-\mathrm{C}-\{\mathrm{P}\}-\mathrm{x}-\mathrm{H}-$ $\{L G Y\}-x-C$, where $x$ represents a nonconserved amino acid, and amino acids within brackets are not allowed) that contains the histidine residue of the SPLA $_{2}$ active site, and the 'PA2_ASP (PS00119, Phospholipase $\mathrm{A}_{2}$ aspartic acid active site [LIVMA]C- $\{$ LIVMFYWPCST $\}$-C-D- $\{\mathrm{GS}\}-\{\mathrm{G}\}-\{\mathrm{N}\}-\mathrm{x}-\{\mathrm{QS}\}$-C', where $\mathrm{x}$ represents a nonconserved amino acid, amino acids within curly brackets are not allowed and amino acids within square brackets are allowed) centred on the active site aspartic acid residue and localized towards the C-terminal portion of the molecule [18]. The $\mathrm{Ca}^{2+}$-binding motif, which, for example in mammalian GIB sPLA $_{2} \mathrm{~s}$, is Y-x-G-x-G (where $\mathrm{x}$ represents a nonconserved amino acid) is localized before the histidine catalytic site towards the $\mathrm{N}$-terminus.

Studies of $\mathrm{sPLA}_{2} \mathrm{~s}$ have focussed mainly on eukaryotes [1-4]. However, the availability of molecular data from phylogenetically distant organisms, and the identification of new $\mathrm{sPLA}_{2} \mathrm{~s}$, challenges the current classification system, especially when applied to invertebrate and prokaryote $\mathrm{SPLA}_{2} \mathrm{~S}[1,19-21]$. Despite their potential evolutionary relationships $[22,23]$, the origin and emergence of $\mathrm{sPLA}_{2} \mathrm{~s}$ is still intriguing. Although all $\mathrm{SPLA}_{2} \mathrm{~S}$ share the same catalytic mechanism involving the canonical histidine residue, there is considerable variation in their sequence identity. Based on their identity, members of the GI/II/V/X PLA 2 collection have been designated 'conventional $\mathrm{SPLA}_{2} \mathrm{~s}$ ' and are believed to be evolutionally close, whereas GIII and GXII PLA $A_{2} \mathrm{~s}$ are classified as 'atypical $\mathrm{sPLA}_{2} \mathrm{~s}$ ' and are evolutionally more distant $[4,8]$. In bacteria and fungi there are $\mathrm{SPLA}_{2} \mathrm{~S}$ that show only limited sequence identity with other $\mathrm{sPLA}_{2} \mathrm{~s}[1,16]$, and to date the evolutionary connection between these structurally distant proteins is lacking.

The present study aimed to contribute to the understanding of the origin and evolution of $\mathrm{sPLA}_{2} \mathrm{~s}$ based upon the identification of their conserved domains in a representative collection of prokaryotes and eukaryotes. Recently, based on published data and the collection of well-annotated multiple sequence alignment models of their conserved domains, the family hierarchy of $\mathrm{sPLA}_{2} \mathrm{~s}$ was comprehensively classified in two general collections: 'cd00618 PLA 2_like: Phospholipase $\mathrm{A}_{2}$, a superfamily of secretory and cytosolic phospholipases $\mathrm{A}_{2}$ ' and 'pfam00068: Phospholip_A2_1, Phospholipase $A_{2}$ ' $[24,25]$. In the present study, secreted $\mathrm{PLA}_{2}$ protein sequences retrieved from public databases were classified according to their conserved domain structures. Their sequences were compared and specific motifs within each subfamily group were identified, and, based upon their sequence and structure similarity, a model for their origin and evolution was proposed. 


\section{Results}

\section{Repertoire of prokaryotic and eukaryotic sPLA $\mathbf{A}_{2} \mathrm{~s}$}

A total of 333 sPLA $_{2}$ sequences from a wide range of taxa were retrieved from publicly available databases, and 358 conserved domains within the cd00618 (PLA $2_{-}-$ like) and pfam00068 (Phospholip_A2_1) collections were identified (Tables 1 and S1). Members of the cdcollection identified are grouped into five distinct subfamilies: the 'cd04706 PLA 2_plant: Plant-specific subfamily of Phospholipase $\mathrm{A}_{2}$ '; 'cd00125 $\mathrm{PLA}_{2} \mathrm{c}$ : Phospholipase $A_{2}$, a family of secretory and cytosolic enzymes'; 'cd04707 otoconin_90: Phospholipase A2-like domains present in otoconin-90 and otoconin-95'; 'cd04704 PLA2_bee_venom_like: A subfamily of Phospholipase $\mathrm{A}_{2}$, similar to bee venom $\mathrm{PLA}_{2}$ ' and 'cd04705 PLA 2_group_III_like: A subfamily of Phospholipase $\mathrm{A}_{2}$, similar to human group III PLA ${ }_{2}$. The pfam-collection members are subdivided into "pfam06951: $\mathrm{PLA}_{2} \mathrm{G} 12$, group XII secretory phospholipase $\mathrm{A}_{2}$ precursor' and 'pfam09056 Phospholip_A $\mathrm{A}_{2}$ 3: Prokaryotic phospholipase $\mathrm{A}_{2}$ domain found in $\mathrm{PLA}_{2} \mathrm{~S}$ of bacteria and fungi' [24,25, http://www.ncbi.nlm.nih.gov/cdd].

All conserved domains of $\mathrm{sPLA}_{2} \mathrm{~s}$ identified are present in representatives of the Kingdom Animalia with the exception of cd04706 of the $\mathrm{sPLA}_{2} \mathrm{~s}$ of bacteria and plants (Table 1). Within this Kingdom, sPLA $_{2}$ s containing the conserved domain cd00125 are widespread in organisms ranging from basal metazoa (Porifera, Placozoa, Cnidaria and Rotifera), protostomes (Insects, Nematodes, Molluscs and Arthropods) and early deuterostomes (Echinodermata, Cephalocordata and Tunicata) to teleosts and tetrapods (Amphibia, Aves and Mammalia). The conserved domain cd00125 is typical of GIA, IB, IIA, IIB, IIC, IID, IIE, IIF, $\mathrm{V}$ and $\mathrm{X}$ sPLA $_{2} \mathrm{~s}$. The conserved domain cd04707 was found in the $\mathrm{N}$ - and $\mathrm{C}$-terminal regions of vertebrate otconins. The conserved domains cd04704 and cd04705 are present in metazoan GIII $\mathrm{PLA}_{2} \mathrm{~S}$, the latter domain exclusively in mammals. The $\mathrm{SPLA}_{2} \mathrm{~S}$ of bacteria contain either cd04706 or pfam09056 (present in XIV $\mathrm{PLA}_{2} \mathrm{~s}$ ) and exceptionally pfam06951. In contrast, no $\mathrm{sPLA}_{2} \mathrm{~S}$ were found in archaea. Pfam09056 is present in the $\mathrm{SPLA}_{2} \mathrm{~s}$ of fungi. The majority of plant $\mathrm{SPLA}_{2} \mathrm{~s}$ contained the conserved domain cd04706 (identified in XIA and XIB $\left.\mathrm{PLA}_{2} \mathrm{~s}\right)$. The conserved domain pfam06951 is present in the GXIIA PLA $\mathrm{PL}_{2} \mathrm{~s}$ of unicellular and multicellular organisms, including marine algae and bacteria (Tables 1 and S1).

\section{Conserved domain cd04706 of PLA $\mathrm{A}_{2} \mathrm{~s}$ of bacteria and plants}

The $\mathrm{sPLA}_{2} \mathrm{~S}$ of bacteria and plants share a number of conserved structural features for the histidine and aspartic acid catalytic motifs and $\mathrm{Ca}^{2+}$-binding domains (Fig. 1). The conserved domain cd04706 was identified in the $\mathrm{SPLA}_{2} \mathrm{~S}$ of bacteria of the class Alphaproteobacteria of the phylum Proteobacteria and also in those of the phylum Firmicutes, which includes both Gram-negative and Gram-positive bacteria, such as the human pathogens Streptococcus pyogenes, Clostridium perfringens, Clostridium botulinum and Bacillus cereus [26] (Table S1). Secreted $\mathrm{PLA}_{2} \mathrm{~S}$ containing cd04706 were also identified in numerous plants. The $\mathrm{SPLA}_{2} \mathrm{~s}$ of $O$. sativa are well characterized and classified as GXI $\mathrm{PLA}_{2} \mathrm{~S}$ [15,27]. In general, several GXI PLA 2 isoforms were identified in plants, which may have resulted from gene-duplication events, for example, four GXI PLA 2 s were identified in O. sativa (Table S1). The GXIB PLA 2 of $O$ sativa is a $16.6 \mathrm{kDa}$ protein in which the $\mathrm{Ca}^{2+}$-binding site contains tyrosine, glycine and aspartic acid residues, and the histidine residue of the active site is centred in the catalytic site motif (Fig. 1A).

Table 1. Distribution of the conserved domains of $\mathrm{SPLA}_{2}$ in the Kingdoms of Life. +, presence; -, absence.

\begin{tabular}{|c|c|c|c|c|c|c|}
\hline $\mathrm{PLA} \mathrm{A}_{2}$ conserved domain & Group number ${ }^{a}$ & Archaea & Bacteria & Viridiplantae & Fungi & Animalia \\
\hline cd00125 & $I A, I B,\|A\| B,,\|C\| D,,\|E\| F, V, X$, & - & - & - & - & + \\
\hline cd04704 & III & - & - & - & - & + \\
\hline $\mathrm{cd} 04705^{\mathrm{b}}$ & III & - & - & - & - & + \\
\hline cd04706 & $X I A, X I B$ & - & + & + & - & - \\
\hline cd04707 & Otoconin & - & - & - & - & + \\
\hline pfam06951 & $X I I A, X I I B$ & - & + & + & + & + \\
\hline pfam09056 & XIV & - & + & - & + & + \\
\hline
\end{tabular}

${ }^{a}$ Group number according to the classification in Schaloske and Dennis [1]. ${ }^{b}$ cd04705 is found only in mammalian GIII PLA 2 . 


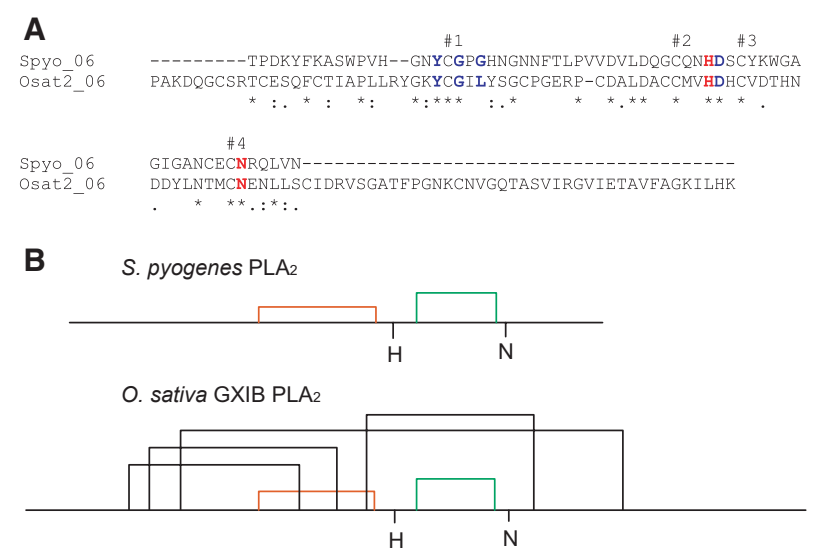

Fig. 1. Alignment of the conserved domain cd04706 sequences of Streptococcus pyogenes sPLA (Spyo_06) and Oryza sativa GXIB $\mathrm{PLA}_{2}$ (Osat2_06) (A) and the positions of the disulfide bonds (B). In panel $A$ the four conserved cysteine $(C)$ residues are indicated with ' $\#$ ' and the conserved putative catalytic histidine $(\mathrm{H})$ and asparagine (N) residues are highlighted in red and the $\mathrm{Ca}^{2+}$-binding residues tyrosine (Y), glycine (G) and aspartic acid (D) are highlighted in blue. The consensus symbols denote the degree of conservation: '*', identical residues; ' $:$ ', conserved substitutions; and '. ', semiconservative substitutions. In (B) the conserved disulfide bonds $\mathrm{C}_{1}-\mathrm{C}_{2}$ and $\mathrm{C}_{3}-\mathrm{C}_{4}$ are red and green, respectively. $\mathrm{H}$ and $\mathrm{N}$ mark the histidine and asparagine residues of the catalytic sites, respectively. The solid horizontal line represents the mature peptide region.

Sequence comparisons revealed that the plant (O. $s a$ tiva) and bacterial (S. pyogenes) sPLA $_{2} \mathrm{~s}$ share $17 \%$ amino acid sequence identity. In both proteins, there is an asparagine residue in the $\mathrm{C}$-terminal portion of the molecule, which probably contributes to the catalytic function [15], instead of the more commonly occurring aspartic acid residue. In the GXIB $\mathrm{PLA}_{2}$ of $O$. sativa there are 12 cysteine residues that form six disulfide bonds [15], while the conserved domain of $S$. pyogenes $\mathrm{sPLA}_{2}$ contains five cysteine residues, four of which $\left(\mathrm{C}_{1}-\mathrm{C}_{2}\right.$ and $\left.\mathrm{C}_{3}-\mathrm{C}_{5}\right)$, align with the plant GXIB PLA cysteines $\left(\mathrm{C}_{4}-\mathrm{C}_{8}\right.$ and $\left.\mathrm{C}_{9}-\mathrm{C}_{10}\right)$ and form conserved disulfide bonds, and are suggestive of structural similarity (Fig. 1B).

\section{Conserved domain cd00125 of PLA $\mathrm{A}_{2}$ of animals}

The conserved domain cd00125 was identified in the basal invertebrates Placozoa up to mammals and was prevalent in the vertebrate GI/II/V/X PLA 2 collection where the functional sites and cysteine residues are highly conserved (Fig. 2). Members of this collection share $26-50 \%$ amino acid sequence identity within the conserved domain region. Among the members of the GI/II/V/X $\mathrm{PLA}_{2}$ collection, the catalytic histidine is centred in the active site motif and the aspartic acid residue of the active site is present in the C-terminal portion of the molecule. In the $\mathrm{Ca}^{2+}$-binding site, $\mathrm{Ca}^{2+}$ is bound by tyrosine and two glycines and an aspartic acid adjacent to the catalytic histidine (Fig. 2).

Homologues of $\mathrm{GI} / \mathrm{II} / \mathrm{V} / \mathrm{X} \mathrm{PLA}_{2}$ collection members are present also in invertebrate genomes, such as the sea anemone Nematostella vectensis, where six genes were identified (Table S1) [28]. The sPLA 2 of the sea anemone Adamsia carciniopados (also called Adamsia palliata) contains the pancreatic loop characteristic of vertebrate GI $\mathrm{PLA}_{2} \mathrm{~S}$ and lacks the C-terminal extension found in GII $\mathrm{PLA}_{2} \mathrm{~S}$ but shares homology for both GI and GII PLA 2 S [19]. Comparison of the disulfide bond positions of the $A$. carciniopados $\mathrm{sPLA}_{2}$ with those of the human GI/II/V/X PLA 2 collection indicates that the sea anemone $\mathrm{SPLA}_{2}$ shares five conserved disulfide bonds with the vertebrate homologues, suggesting structural, and possibly functional, conservation across the phylogenetically distant organisms of Cnidaria and Mammalia (Fig. 3).

\section{Conserved domain cd04707 of otoconins}

Otoconins containing the conserved domain cd04707 were identified in a number of vertebrates, from fish to mammals, and two conserved domains within the $\mathrm{N}$-terminal (OtoN) and C-terminal (OtoC) regions of the same collection were identified within the mature protein sequence (Tables 1 and S1). The human otoconin-90 is a $53 \mathrm{kDa}$ protein, and the OtoN and OtoC domains are $37 \%$ identical and structurally closely related to the members of the GI/II/V/X PLA 2 collection, suggesting common ancestry (Fig. 2). The human OtoN and OtoC domains are $36 \%$ and $34 \%$ identical, respectively, when compared with GIB PLA 2 . Moreover, the disulfide bond patterns of human otoconin and GIB $\mathrm{PLA}_{2}$ are identical (Fig. 3). Both OtoN and OtoC domains contain a histidine residue within the conserved catalytic site. However, they are believed to be catalytically inactive as a result of mutations in the $\mathrm{Ca}^{2+}$-binding sites (Fig. 2), leading to loss of the usual $\mathrm{Ca}^{2+}$-binding residues in the OtoN domain, and in the OtoC domain the conserved second glycine of the mammalian GIB PPLA $_{2} \mathrm{~s}(\mathrm{Y}-\mathrm{x}-\mathrm{G}-\mathrm{x}-\mathrm{G})$ is replaced with a glutamic acid, although $\mathrm{PLA}_{2}$ activity remains to be investigated [29].

\section{Conserved domain cd04704 of group III PLA $\mathrm{A}_{2} \mathrm{~s}$}

Secreted $\mathrm{PLA}_{2} \mathrm{~S}$, containing the conserved domain

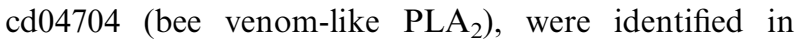
arthropods, reptiles and vertebrates, including humans. 


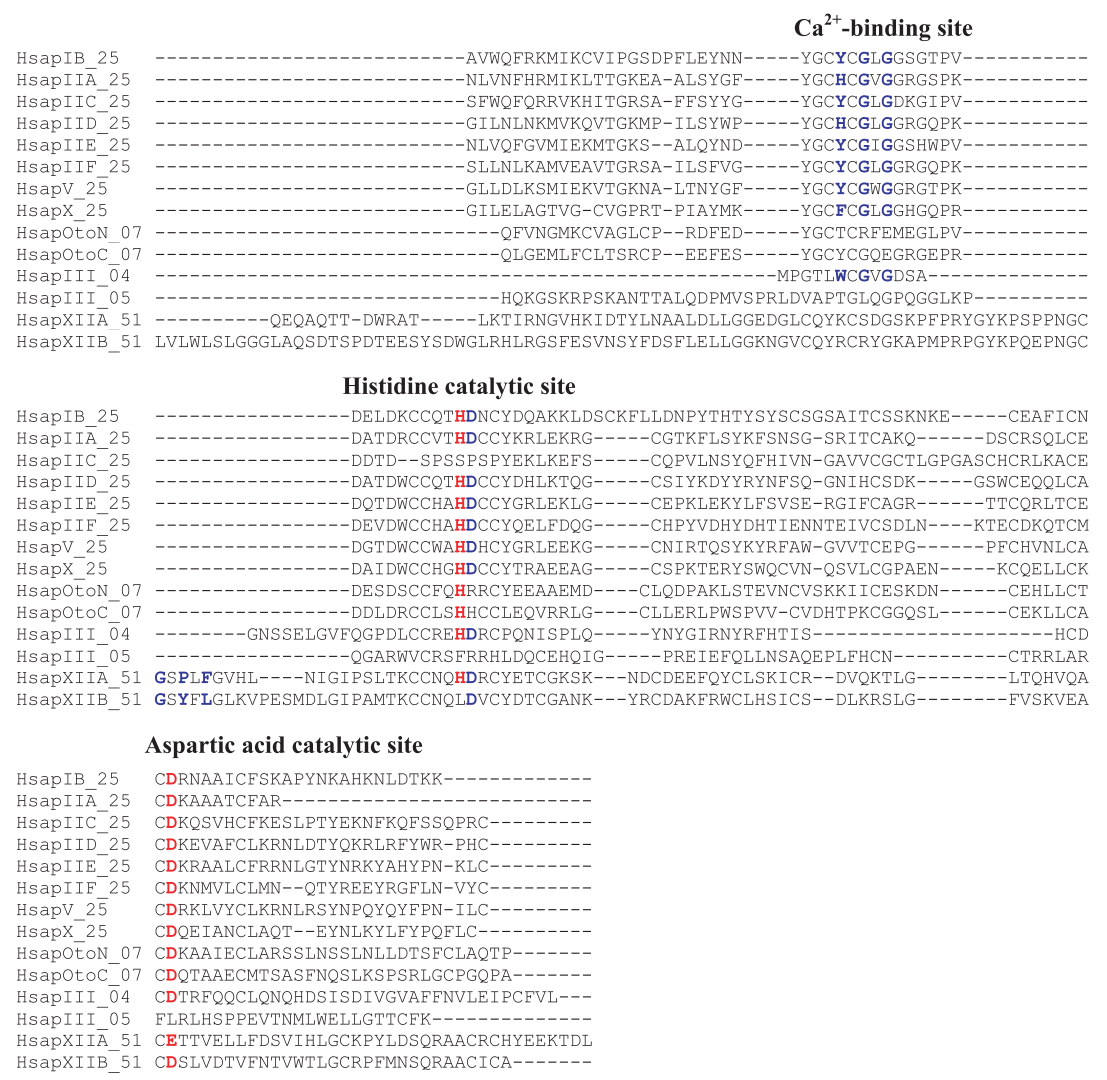

Fig. 2. Multiple sequence alignment of the conserved domains of human sPLA 2 S. HsaplB_25 (GIB PLA 2 ), HsaplIA_25 (GIIA), HsaplIC_25 (GIIC), HsaplID_25 (GIID), HsaplIE_25 (GIIE), HsaplIF_25 (GIIF), HsapV_25 (GV) and HsapX_25 (GX) PLA 2 S contain the conserved domain cd00125 and belong to the structurally related GI/II/V/X PLA 2 collection. HsaplII_04 and HsaplII_05 (GIII PLA ${ }_{2}$ ) represent cd04704 and cd04705, respectively. HsapGXIIA_51 and HsapGXIIB_51 (GXIIA and GXIIB PLA 2 S) contain pfam06951. HsapOtoN_07 and HsapOtoC_07 contain the $\mathrm{N}$ - and C-terminal sections of cd04707 of otoconin-90, respectively. The catalytic histidine (H), aspartic acid (D) and asparagine (N) residues are highlighted in red, and the $\mathrm{Ca}^{2+}$-binding amino-acid residues tyrosine (Y), glycine (G), histidine $(\mathrm{H})$, phenylalanine $(\mathrm{F})$, tryptophan $(W)$, proline $(P)$, leucine $(L)$ and aspartic acid $(D)$ are highlighted in blue.

The honeybee Apis mellifera venom GIII PLA 2 shares considerable sequence identity with the members of the $\mathrm{GI} / \mathrm{II} / \mathrm{V} / \mathrm{X} \mathrm{PLA}_{2}$ collection (e.g. $44 \%$ identity with the human GIB PLA 2 ) and is related in its 3D structure and catalytic mechanism to GI and GII PLA 2 S [11,17]. The backbone of the GIII PLA 2 molecule contains the conserved $\mathrm{Ca}^{2+}$-binding loop with tryptophan, glycine and aspartic acid residues and the conserved catalytic histidine and aspartic acid residues (Fig. 4). Human

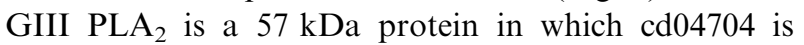
localized in the middle part of the molecule and flanked by $\mathrm{N}$ - and C-terminal extensions [30]. The cd04704 of human GIII PLA 2 displays features similar to the arthropod GIII $\mathrm{PLA}_{2} \mathrm{~s}$, including the $\mathrm{Ca}^{2+}$ binding and catalytic site residues and also the 10 conserved cysteines that form five disulfide bonds at similar locations, and shares $44 \%$ sequence identity with honeybee venom GIII PLA 2 .

\section{Conserved domain cd04705 of group III PLA 2}

Proteins containing the conserved domain cd04705 (similar to human group III PLA $\mathrm{PL}_{2}$ ) were found only in mammals (Table 1). The conserved domain cd04705 is localized in the C-terminal part of the GIII PLA Pol- $_{2}$ ecule and is structurally unrelated to cd04704 (Fig. 2). In contrast to cd04704, cd04705 is considered to be catalytically inactive and its function is unknown [30].

\section{Conserved domain pfam09056 of PLA $2 \mathrm{~s}$ of bacteria, fungi and animals}

The conserved domain pfam09056 (prokaryotic $\mathrm{PLA}_{2}$ ) was identified in the $\mathrm{sPLA}_{2} \mathrm{~s}$ of Gram-positive and Gram-negative bacteria, protists, fungi and marine invertebrates of the phyla Cnidaria and Mollusca. Bacterial $\mathrm{sPLA}_{2} \mathrm{~s}$ containing pfam09056 are markedly 

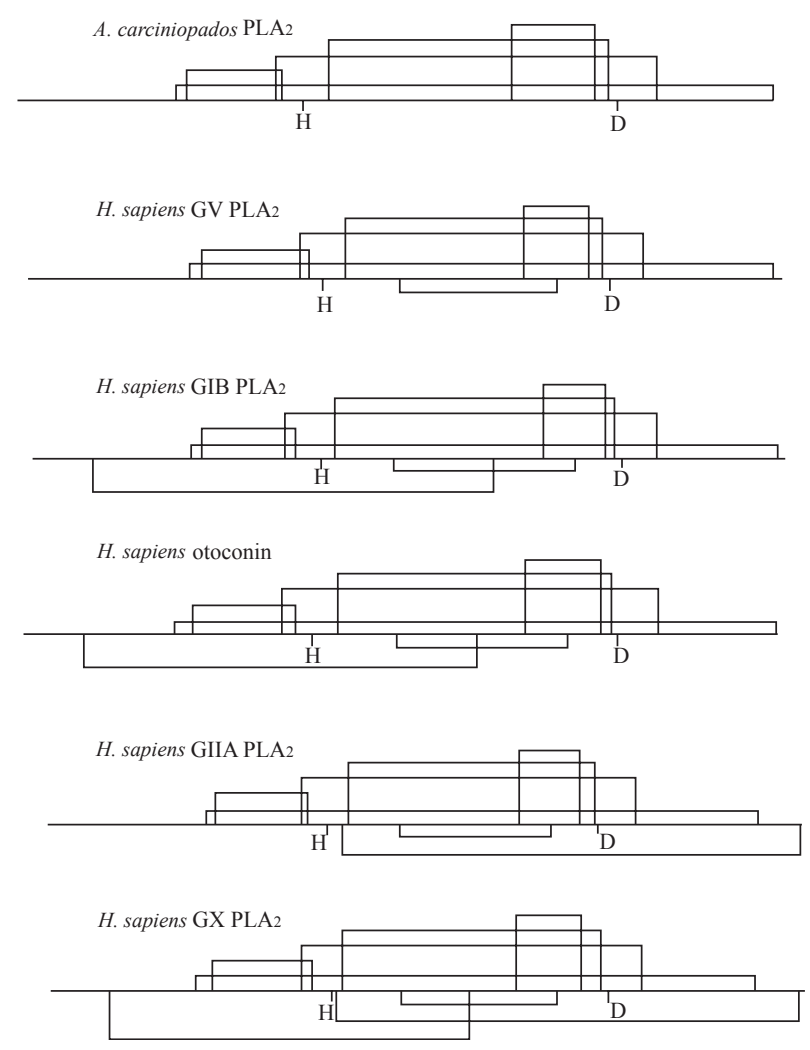

Fig. 3. Comparison of the disulfide bond positions in the cnidarian Adamsia carciniopados and human GV, GIB, GIIA and GX PLA 25 and otoconin-90. Five disulfide bonds are conserved from the cnidarian to the human. Histidine $(H)$ and aspartic acid (D) are the active-site amino acid residues of the $P L A_{2} s$, and the corresponding residues are present in otoconin. The basal line represents the mature peptide region.

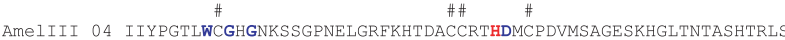
HsapIII_04 -TMPGTLWCGVGDSAGNSSELGVFQGPDLCCREHDRCPQNISPLQYNYGIRNYRFHTISH

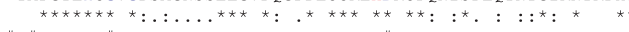
$\#$

AmelIII 04 CDCDDKFYDCLLNSSADTISSYFVGKMYFNLIDTKCYKI

HSAPIII_04 CDCDTRFQQCLQNQHDSIS-DIVGVAFFNVLEIPCFVL

Fig. 4. Alignment of the conserved domains cd04704 of the

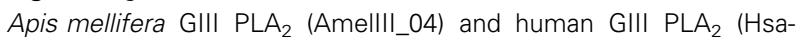
pllI_04). The $\mathrm{Ca}^{2+}$-binding residues tryptophan (W), glycine (G) and aspartic acid (D) are highlighted in blue, the catalytic histidine $(H)$ and aspartic acid (D) are highlighted in red, and the conserved cysteine $(C)$ residues are indicated with '\#'.

different in their molecular structure from the bacterial $\mathrm{sPLA}_{2} \mathrm{~s}$ containing cd04706. Comparison of the conserved domains of Streptomyces violaceoruber (pfam09056) and $S$. pyogenes (cd04706) $\mathrm{sPLA}_{2}$ s indicates that they share only $8 \%$ sequence identity. The catalytic motif of the $\mathrm{SLA}_{2}$ of the Gram-positive bacterium S. violaceoruber [16,31] contains the conserved histidine and aspartic acid residues (Figs 2 and 5). The conserved

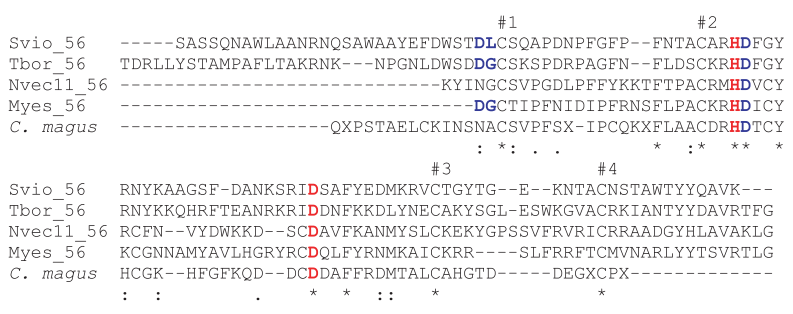

Fig. 5. Comparison of the conserved domains pfam09056 of Streptomyces violaceoruber (Svio_56), Tuber borchii (Tbor_56), Nematostella vectensis (Nvec11_56) and Mizuhopecten yessoensis (Myes_56) sPLA 2 s with the GIX PLA 2 of Conus magus. Four cysteine residues ( $\mathrm{C}$, marked with '\#') and the histidine $(\mathrm{H})$ and aspartic acid (D) residues of the active site (highlighted in red) are conserved. The putative $\mathrm{Ca}^{2+}$-binding residues aspartic acid (D), glycine $(\mathrm{G})$ and leucine $(\mathrm{L})$ are shown in blue. There are two putative disulfide bonds between the conserved cysteines $C_{1}-C_{2}$ and $C_{3}-C_{4}$.

$\mathrm{Ca}^{2+}$-binding domain is absent and the binding of $\mathrm{Ca}^{2+}$ is mediated via the aspartic acid and leucine residues upstream of the catalytic site and by the aspartic acid residue adjacent to the catalytic histidine residue (Figs 2 and 5). There are four cysteines that form two putative disulfide bonds, including a bond that connects the catalytic and the $\mathrm{Ca}^{2+}$-binding sites (Fig. 5).

In addition to bacteria, $\mathrm{sPLA}_{2} \mathrm{~S}$ containing pfam09056 were also identified in both unicellular and multicellular fungi. The $\mathrm{SPLA}_{2}$ of the fungus Tuber borchii [32] is a $23 \mathrm{kDa}$ protein that contains two conserved disulfide bonds analogous to those of the $\mathrm{sPLA}_{2}$ of $S$. violaceoruber (Fig. 5), and the two conserved domains are $42 \%$ identical.

There are pfam09056-containing $\mathrm{sPLA}_{2} \mathrm{~s}$ in aquatic invertebrates of the phylum Cnidaria, including the sea anemone $N$. vectensis and the hydrozoan Hydra magnipapillata. Cnidarian $\mathrm{sPLA}_{2} \mathrm{~s}$ have the conserved catalytic histidine and aspartic acid residues but contain more numerous cysteine residues and putative disulfide bonds than the corresponding bacterial and fungal sPLA $_{2}$ s (Fig. 5).

Recently, expressed sequence tags (ESTs), coding for potential $\mathrm{sPLA}_{2} \mathrm{~S}$ containing the conserved domain pfam09056, were identified in the protist Astrammina rara (phylum Foramifera) and the scallop Mizuhopecten yessoensis (phylum Mollusca) [33]. Previously, a related $\mathrm{SPLA}_{2}$ was isolated from the venom of another mollusc - the marine snail Conus magus - and classified as GIX PLA 2 [34] but no conserved domain was identified for this protein in the present study, probably because of the incompleteness of its sequence. However, conserved histidine and aspartic acid activesite motifs are present in the pfam09056-containing sPLA $_{2} \mathrm{~S}$ of the scallop M. yessoensis and the sea anemone $N$. vectensis and in the GIX PLA 2 of the 
Fig. 6. Consensus bootstrap phylogenetic tree of the $\mathrm{SPLA}_{2}$ conserved domains. The tree was constructed with 53 taxa (see Table $\mathrm{S} 1$ for details) and using the NJ method. The percentage of replicate trees in which the associated taxa clustered together in the bootstrap test (1000 replicates) are shown next to the branches, and bootstrap branches lower than 50 were collapsed. Acap_56, Ajellomyces capsulata (Fungi); AmellII_04, Apis mellifera (Insecta); Aory2_56, Aspergillus oryzae (Fungi); Bbac_56, Bdellovibrio bacteriovorus (Deltaproteobacteria); BtaullI_05, Bos taurus (Mammalia); Cfamlll_05, Canis familiaris (Mammalia); Cglo_56, Chaetomium globosum (Fungi); Cimm_56, Coccidioides immitis (Fungi); Crei_06, Chlamydomonas reinhardtii (Viridiplantae); Dcar_06, Dianthus caryophyllus (Viridiplantae); Dgeo_56, Deinococcus geothermalis (Deinococci); Dmel_25, Drosophila melanogaster (Insecta); DmelXIIA_51, Drosophila melanogaster (Insecta); Fsp_56, Frankia sp. (Actinobacteria); GgalOtoN_07, Gallus gallus (Aves); Hmag_56, Hydra magnipapillata (Cnidaria); HsapllI_05, Homo sapiens (Mammalia); HsapOtoN_07, Homo sapiens (Mammalia); HsapXIIA_51, Homo sapiens (Mammalia); Hsp_56, Helicosporium sp. (Fungi); HsusIII2_04, Heloderma suspectum (Anguimorpha); IpacXIIA_51, Ixodes pacificus (Arachnida); Iscalll_04, Ixodes scapularis (Arachnida); MdomXIIA_51, Monodelphis domestica (Mammalia); Medu_25, Mytilus edulis (Mollusca); Mext2_06, Methylobacterium extorquens (Alphaproteobacteria): Mgri1_56, Magnaporthe grisea (Fungi); MmusIIA_25, Mus musculus (Mammalia); MmusIII_05, Mus musculus (Mammalia); MmusOtoC_07, Mus musculus (Mammalia); MmusOtoN_07, Mus musculus (Mammalia); MmusXIIA_51, Mus musculus (Mammalia); Mnod2_06, Methylobacterium nodulans (Alphaproteobacteria); Mrad_06, Methylobacterium radiotolerans (Alphaproteobacteria); Mtru_06, Medicago truncatula (Viridiplantae); Ntab 2_06, Nicotiana tabacum (Viridiplantae); Nvec10_56, Nematostella vectensis (Cnidaria); Nvec11_56, Nematostella vectensis (Cnidaria); Nvec12_65, Nematostella vectensis (Cnidaria); Nvec13_56, Nematostella vectensis (Cnidaria); OanalB_25, Ornithorhynchus anatinus (Monotremata); OhanIA_25, Ophiophagus Hannah (Reptilia); Osat2_06, Oryza sativa (Viridiplantae); PperllI_04, Phlebotomus perniciosus (Insecta); Scoe1_56, Streptomyces coelicolor (Actinobacteria); Sequ_06, Streptococcus equi (Firmicutes); Sery_56, Saccharopolyspora erythraea (Actinobacteria); Spyo_06, Streptococcus pyogenes (Firmicutes); Svio_56, Streptomyces violaceoruber (Actinobacteria); TgutXIIA_51, Taeniopygia guttata (Aves); TnigOtoC_07, Tetraodon nigroviridis (Teleostei); XlaeXIIA_51, Xenopus laevis (Amphibia); Xtrolll_04, Xenopus tropicalis (Amphibia).

snail C. magus (Fig. 5). Furthermore, the GIX PLA 2 of C. magus shares $13-33 \%$ sequence identity with the bacterial, fungal and cnidarian pfam09056 $\mathrm{PLA}_{2} \mathrm{~s}$, but lower identity of $9-13 \%$ with the cd04706, cd04704 and cd00125 $\mathrm{PLA}_{2} \mathrm{~s}$.

\section{Conserved domain pfam06951 of GXII PLA ${ }_{2} \mathrm{~S}$}

GXIIA PLA 2 was first cloned from human [35]. In the present study, the conserved domain pfam06951 was identified in the GXII PLA ${ }_{2}$ s of a large number of vertebrate and invertebrate species, including the basal metazoans N. vectensis (Cnidaria), Trichoplax adhaerens (Placozoa) and Brachionus plicatus (Rotifera), as well as in the nonmetazoan eukaryotes (protists), such as the amoeba Naegleria gruberi (Heterolobosea), Monosiga ovata (Choanoflagellida), Euglena gracilis (Euglenozoa), Phytophthora infestans (Oomycetes), Thalassiosira pseudonana (Bacillariophyta), Capsaspora owczarzaki (Ichthyosporea), Chromera velia (Alveolata) and Thecamonas trahens (Apusozoa). Furthermore, pfam06951 was also identified in the $\mathrm{SPLA}_{2} \mathrm{~s}$ of the marine algae Micromonas (Viridiplantae) and the prokaryote Planctomyces maris (Bacteria) (Table S1). These observations demonstrate that the conserved domain pfam06951 is widely distributed not only in the $\mathrm{PLAA}_{2} \mathrm{~S}$ of higher animals but also in the $\mathrm{SPLA}_{2} \mathrm{~S}$ of simple eukaryotes and prokaryotes. Sequence alignment of the GXIIA PLA P $_{2}$ conserved domains of organisms ranging from protists to mammals reveals high conservation of the $\mathrm{Ca}^{2+}$-binding and catalytic sites. The canonical his- tidine catalytic site C-C-x-x-H-x-x-C motif is highly conserved. In the aspartic acid catalytic motif, the cysteine and aspartic acid residues are also conserved, with the exception of E. gracilis (Euglenozoa), Micromonas pusilla (Viridiplantae) and P. infestans (Oomycetes), in which aspartic acid is replaced by glutamic acid and the first cysteine is absent in all the sequences (Fig. S1). Comparison of the human GXIIA PLA 2 (pfam06951) with GIB PLA 2 (cd00125) indicated 37\% amino acid sequence identity.

Another gene product closely related to GXIIA $\mathrm{PLA}_{2}$ is GXIIB PLA 2 [36]. Human GXIIB PLA shares $46 \%$ sequence identity with GXIIA $\mathrm{PLA}_{2}$. GXIIB PLA 2 is a catalytically inactive protein as a result of the substitution of histidine with leucine in the catalytic site (Fig. 2).

\section{Phylogenetic analysis of $\mathbf{S P L A}_{2} \mathbf{S}$}

Phylogenetic analysis of the conserved domains of $\mathrm{SPLA}_{2} \mathrm{~s}$, carried out with the maximum likelihood (ML) and neighbour-joining (NJ) methods, produced similar tree topologies, suggesting that the members of this protein family have a common and ancient evolutionary origin (Fig. 6). Two major sPLA 2 groups - the cd-collection (which includes the cd00125, cd04704, cd04705, cd04706 and cd04707 of unicellular and multicellular organisms) and the pfam-collection (which contains the $\mathrm{SPLA}_{2} \mathrm{~S}$ with the annotated pfam06951 and pfam09056 domains) - exist and underwent distinct trajectories during evolution. 


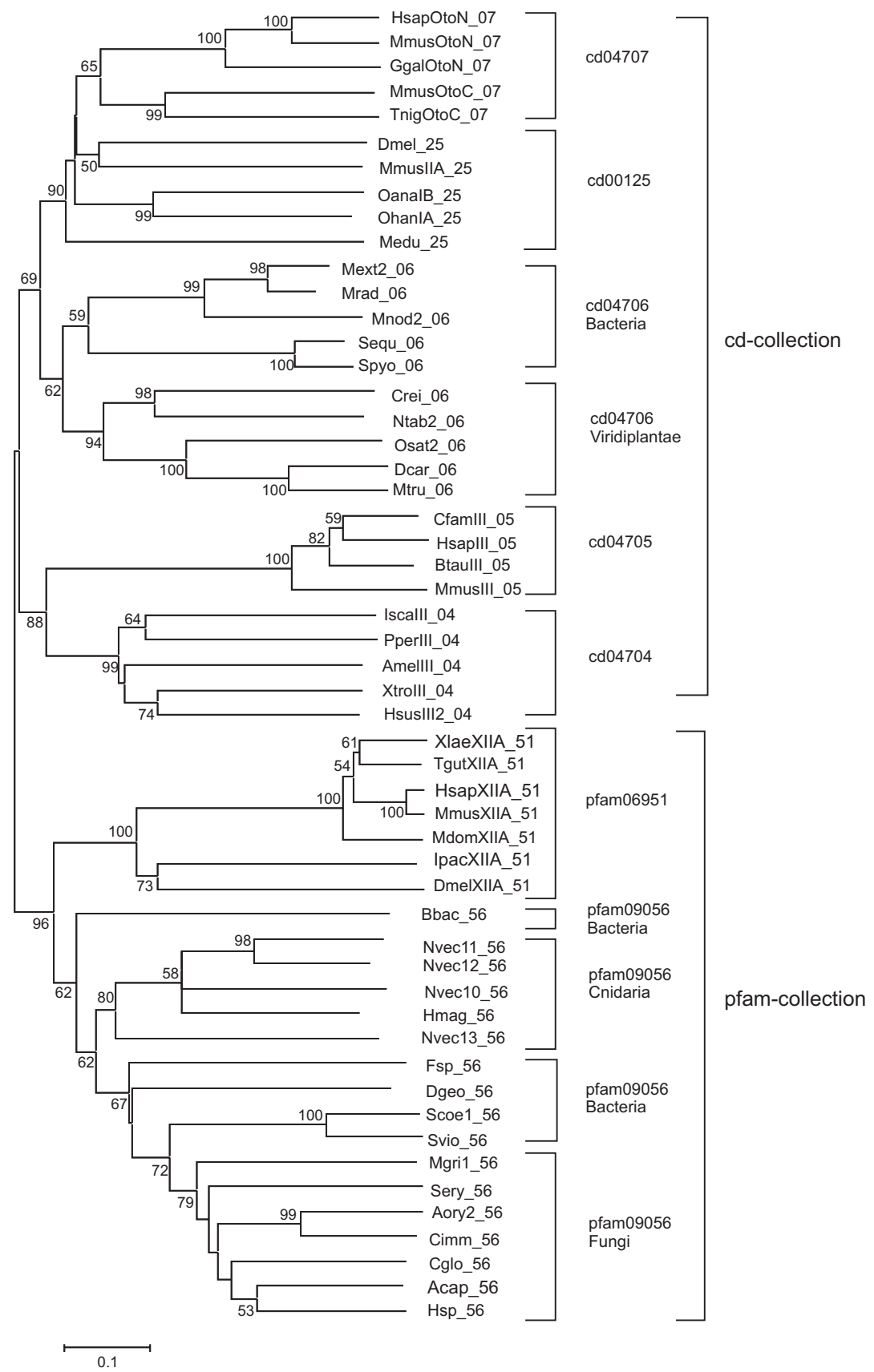

The $\mathrm{SPLA}_{2}$ forms of bacteria cluster within each $\mathrm{PLA}_{2} \mathrm{~S}$ subgroup, suggesting that the eukaryote and prokaryote $\mathrm{SPLA}_{2}$ repertoire share a $\mathrm{PLA}_{2}$-like common ancestor molecule, which remains to be identified. The cd-collection contains the majority of the $\mathrm{SPLA}_{2}$ sequences identified, and the clustering observed indicates that discrete relationships between the $\mathrm{SPLA}_{2}$ protein groups exist (Fig. 6). Members of the cd04704 and cd04705 groups seem to have evolved separately from the other cd-collection members, such as cd00125 and cd04707, and have only been identified in animals.

\section{Discussion}

$\mathrm{PLA}_{2}$ activity was first reported in canine pancreatic juice [37] and $\mathrm{SPLA}_{2}$ s have now been isolated from a large number of snake and other venoms, and also from cells, tissues and body fluids of various unicellular and multicellular organisms [38-40]. Initially, sPLA $_{2} \mathrm{~S}$ were classified into two major groups of GI and GII PLA $\mathrm{P}_{2}$ s [41], but subsequent sequence homology and conserved disulfide bonds were observed within the other members of the GI/II/V/X PLA 2 col- 
lection and the related protein otoconin [42]. This classification has been expanded and refined over the past two decades as information from phylogenetically distinct organisms has accumulated at an accelerating rate $[1,2,8,23]$. The recent systematic identification of the conserved domains of protein molecules [24,25] allows a novel classification of the $\mathrm{sPLA}_{2} \mathrm{~s}$ ('cd/pfam classification') based on the identification of the conserved domains, and a meaningful phylogenetic analysis of the whole range of $\mathrm{SPLA}_{2} \mathrm{~s}$.

The aim of the present study was to elucidate the origin and evolution of the $\mathrm{sPLA}_{2} \mathrm{~s}$. The enormous evolutionary span between the organisms expressing $\mathrm{SPLA}_{2} \mathrm{~S}$ (ranging from prokaryotes to metazoan eukaryotes) by necessity introduces a degree of uncertainty in the comparison of protein sequences between such distant phyla. When $\mathrm{PLA}_{2}$ sequences containing conserved domains of different groups are compared, the molecular structure of a particular $\mathrm{PLA}_{2}$ reflects the divergent or convergent evolution of the conserved domain structure and the evolutionary history of the organism in question. In the present study, we investigated the structural variability of the conserved domains of $\mathrm{SPLA}_{2} \mathrm{~s}$ in a wide range of organisms, from bacteria to mammals. A total of 358 conserved domains were identified among 333 $\mathrm{sPLA}_{2}$ sequences. In viruses, $\mathrm{SPLA}_{2}$-like proteins (GXIII PLA ( $_{2}$ have also been reported but their molecular structure, including the conserved domain and the enzymatic activity, differ from those of $\mathrm{sPLA}_{2} \mathrm{~s}$ [43] and thus were not included in the current analysis.

Two main distinct forms of $\mathrm{SPLA}_{2} \mathrm{~s}$ were identified in bacteria: those containing cd04706 (bacteria/plantspecific subfamily of $\mathrm{PLA}_{2}$ ) and those containing pfam09056 (prokaryotic/fungal $\mathrm{PLA}_{2}$ ). Notably, no ${ }_{\mathrm{SPLA}} \mathrm{S}$ were identified in the Archaea. A marked difference between Bacteria and Archaea is that the predominant lipid constituents of the archaean membranes are prenyl ether lipids, whereas the bacterial membranes contain acyl ester lipids [44-46]. The phospholipid metabolism of bacteria is driven by phospholipases that specifically hydrolyze the acyl ester bonds but are incapable of hydrolyzing the prenyl ether lipids. In light of this observation, it is hypothesized that the $\mathrm{sPLA}_{2} \mathrm{~s}$ of the higher organisms may have their evolutionary origin in Bacteria rather than in Archaea.

Members of the $\mathrm{SPLA}_{2} \mathrm{~S}$ are proposed to share a common ancestry and to have emerged early in evolution, and several theories based upon their sequence similarities and predicted molecular structure have suggested that they evolved rapidly. The GI and GII $\mathrm{sPLA}_{2} \mathrm{~s}$ of Elapidae and Crotalidae snake venoms, respectively, have distinct molecular structures and it has been proposed that they share a common ancestor [22]. Snake venom $\mathrm{sPLA}_{2} \mathrm{~s}$ are suggested to have evolved at an accelerated rate that has resulted in the presence of many variant $\mathrm{PLA}_{2}$ molecules produced by the venom glands [40,47-49].

A recent example of the rapid evolution of $\mathrm{sPLA}_{2}$ genes is the bovine GIID PLA $\mathrm{PL}_{2}$. In cattle, five duplications have been identified, while a single gene copy is present in the human and rodent genomes. The bovine GIID $\mathrm{PLA}_{2} \mathrm{~S}$ are expressed in the mammary gland and up-regulated during the lactating period, and are suggested to participate in the innate immune response [50]. In human and mouse, GIIA, GIIC, GIID, GIIE, $G I I F$ and $G V P L A_{2}$ genes are also the result of geneduplication events within the same chromosome. In human they are localized in chromosome 1, whereas $G I B$ and $G X$ genes map to chromosomes 12 and 16 , respectively. However, comparisons between the gene homologues in human and mouse reveal that speciesspecific events may occur; for example, the human GIIC $P \mathrm{LA}_{2}$ is a pseudogene, whereas the mouse homologue encodes an enzymatically active protein [51]. Another example of the functional diversity within the members of the GI/II/V/X PLA 2 collection are the human and mouse GIIA $\mathrm{PLA}_{2} \mathrm{~s}$, which are efficient bactericidal enzymes involved in the innate immune response, whereas the closely related digestive enzyme GIB PLA $_{2}$ is only marginally bactericidal [6,52]. For example, in vitro assays demonstrated that Gram-positive bacteria are killed by $\mathrm{sPLA}_{2} \mathrm{~s}$ and that human GIIA PLA $_{2}$ is highly potent in this respect, whereas GIB PLA $\mathrm{PL}_{2}$ is of low efficacy [52].

In Cnidaria, a sister group of the vertebrate clade that diverged more than 500 million years ago $[53,54], \mathrm{sPLA}_{2} \mathrm{~s}$ have been reported that structurally resemble the vertebrate GI and GII PLA ${ }_{2} \mathrm{~S}$ [1921,28]. Our current observations indicate that a cnidarian sPLA $_{2}$ [19] containing cd00125 has disulfide bonds at locations identical to those of the human GV PLA $_{2}$ and conserved in other members of the $\mathrm{GI} / \mathrm{II} / \mathrm{V} / \mathrm{X} \mathrm{PLA}_{2}$ collection. Group $\mathrm{I} \mathrm{PLA}_{2} \mathrm{~S}$ of elapid snake venoms have lost the ancestral pancreatic loop present in the cnidarian $\mathrm{SPAA}_{2}$ and also in the mammalian GIB PLA 2 . Such structural changes have resulted in the appearance of novel functions, including toxicity of the venom $\mathrm{sPLA}_{2} \mathrm{~s}$ [55]. However, the number of cysteine residues and disulfide bonds of $\mathrm{sPLA}_{2} \mathrm{~S}$ vary among closely related animals such as the sea anemones Adamsia carcinipados, Urticina crassicornis, Condylactis gigantea and $N$. vectensis [19-21,28,56]. The variation in the disulfide patterns and other structural features seems to preclude the 
exact placement of these cnidarian ${ }_{5} \mathrm{PLA}_{2} \mathrm{~s}$ in the currently recognized groups of the GI/II/V/X $\mathrm{PLA}_{2}$ collection [19-21].

In the current study, homologues of the vertebrate GXII members with highly conserved domain regions were identified for the first time in unicellular organisms, and their function in such organisms remains to be established. In human, GXIIA PLA 2 is expressed in $\mathrm{T}$ lymphocytes and seems to be involved in the regulation of the immune response [57]. Human GXIIB $\mathrm{PLA}_{2}$ was recently shown to be involved in the triglyceride metabolism in the liver [58] and is proposed to activate specific receptors that remain to be identified [36].

Life as we know it can be divided into the prokaryotic (cellular organisms that lack a nucleus) Domains of Bacteria (Eubacteria) and Archaea (Archaebacteria), and the Domain of Eukaryota (organisms consisting of nucleated cells, such as animals, plants and fungi) [44]. Prokaryotes are the oldest cellular life forms on Earth, dating back 3.5-4 billion years and predating eukaryotes by 1 billion years. The current phylogenetic analysis of the conserved domains of $\mathrm{SPLA}_{2} \mathrm{~s}$ of the representatives of the major prokaryote and eukaryote taxa supports the hypothesis that the $\mathrm{SPLA}_{2} \mathrm{~s}$ of the eukaryotes, including the Metazoa, Viridiplantae and Fungi, may have shared a common origin with their homologues in bacteria. Two $\mathrm{SPLA}_{2}$ groups (the cd-collection and the pfam-collection) emerged early in evolution and underwent distinct evolutionary trajectories. Based upon the retrieved data and phylogenetic relatedness, a model for the evolution of the two $\mathrm{SPLA}_{2} \mathrm{~S}$ group members is proposed centred around gene-duplication and gene-deletion events (Fig. 7A,B). While the two members of the pfam-collection are present in representatives of the Eubacteria and Animalia kingdoms and maintained throughout evolution (Fig. 7B), the cd-collection members seem to have mainly emerged in the Animalia kingdom (Fig. 7A) and their expansion may be associated with the gene duplications that are proposed to have contributed to the increase in organismal complexity during eukaryote evolution [59]. The cd04706 protein members are exclusively found in Eubacteria and Plantae kingdoms and were lost from other life forms. Despite the lack of data from representatives of all clades and the failure to identify homologues it can be hypothesized that in the kingdom Animalia, $\mathrm{sPLA}_{2} \mathrm{~S}$ with the conserved domains cd00125 and cd04704 were the first members to emerge. Subsequently, several independent gene or genome-duplication events occurred and resulted in the emergence of two novel family members of vertebrate cd04704 and mammalian cd04705. The sequence

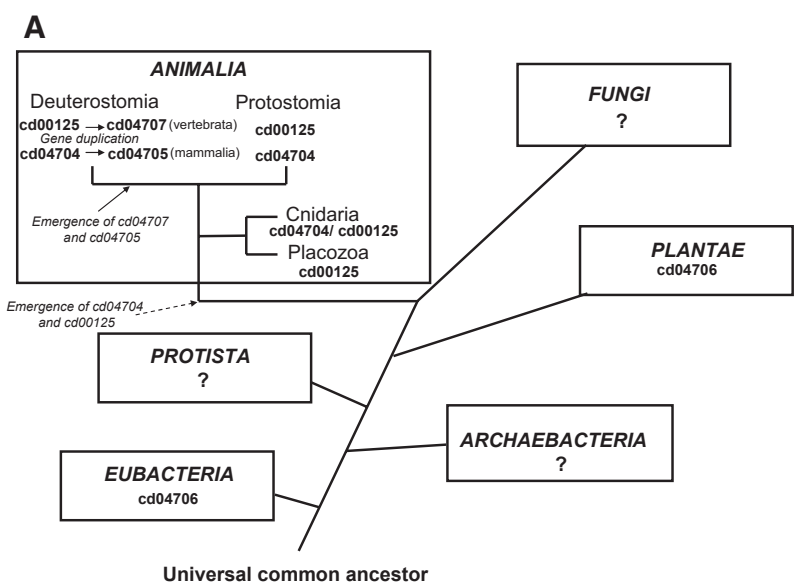

B

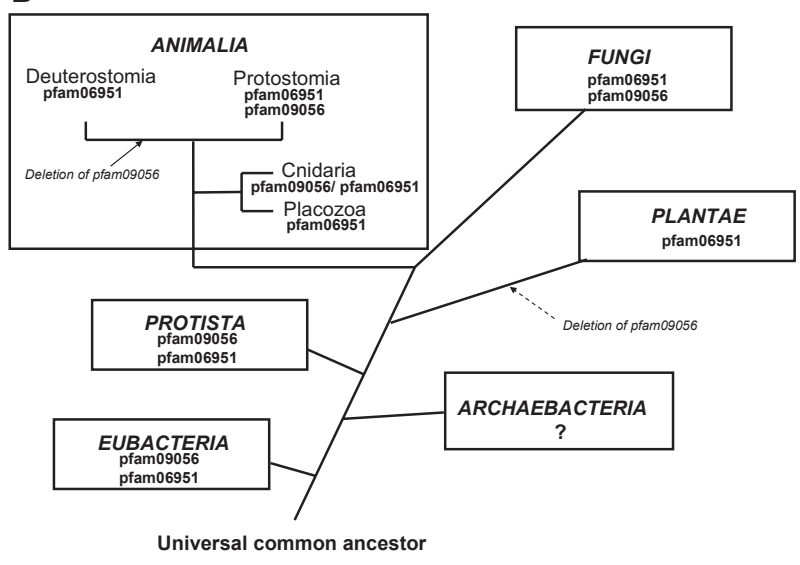

Fig. 7. Proposed evolution of $s P L A_{2} s$ in the six Kingdoms of life (Animalia, Fungi, Plantae, Protista, Archaeobacteria and Eubacteria). Models were constructed using the retrieved data obtained and phylogenetic relationships. (A) Hypothetical evolution of the SPLA 2 cd-collection members. (B) Hypothetical evolution of the pfam-collection members. Dashed arrows indicate unclear evolutionary trajectories and '?' not yet identified.

similarity observed between the vertebrate $\mathrm{SPLA}_{2} \mathrm{~s}$ containing conserved domains cd04707 and cd00125 and also the mammalian cd04705 with cd04704 suggests that they have a shared common origin and that cd04707 emerged from a gene-duplication event of the cd00125-like ancestral gene at the time of vertebrate emergence and that cd04705 resulted from a later gene-duplication event of the cd04704-like ancestral gene precursor within the mammalian lineage (Fig. 7A). In contrast, only fungi, protists and aquatic invertebrates, such as those of the phyla Cnidaria and Mollusca, have acquired pfam09056-containing $\mathrm{sPLA}_{2} \mathrm{~s}$ and the homologue gene seems to have been deleted from Protostomes and Deuterostome genomes (Fig. 7B). 
The present analysis is based on the highly conserved peptide motifs directly involved in the catalytic function of $\mathrm{sPLA}_{2} \mathrm{~s}$, including the $\mathrm{Ca}^{2+}$-binding site and the catalytic centre. However, the functional roles of the surrounding domains are at present less well understood (e.g. the functions of the domains flanking the central catalytically active cd04704 of mammalian GIII PLA $\mathrm{P}_{2} \mathrm{~S}$ are unknown) [3] and their study may provide novel insight into the catalytic and noncatalytic functions of $\mathrm{sPLA}_{2} \mathrm{~s}$. For instance, binding of $\mathrm{SPLA}_{2} \mathrm{~S}$ to specific cellular receptors is independent of their catalytic activity, and the protein domains involved in the receptor activation are not yet fully resolved [4]. Other examples are the toxicity of some snake venom $\mathrm{PLA}_{2} \mathrm{~S}$, which does not correlate with their catalytic activity [8], and the bactericidal effects of $\mathrm{sPLA}_{2} \mathrm{~s}$ lacking catalytic activity [60].

It is concluded that the $\mathrm{SPLA}_{2} \mathrm{~S}$ of eukaryotes share their evolutionary origin with two distinct types of bacterial $\mathrm{sPLA}_{2} \mathrm{~s}$. Their evolution and prevalence in genomes seems to be related to the functional constraints of phospholipid metabolism which is a fundamental and conserved process in organisms. Although relatively little is known about the function of prokayotic $\mathrm{sPLA}_{2} \mathrm{~s}$, the large number of distinct $\mathrm{sPLA}_{2}$ isoforms in metazoans reflects the wide variation of substrate types encountered in the extracellular environment where the enzyme plays many important roles in nutrition, reproduction and immunity.

\section{Material and methods}

\section{Database mining and data collection}

Secreted $\mathrm{PLA}_{2}$ sequences were retrieved from the publicly available protein databases of NCBI (http://www.ncbi.nlm.nih.gov) and Swiss-Prot (http://www.uniprot.org) using the Basic Local Alignment Search Tool (BLASTp) algorithm [61] and default settings. Database searches were performed using the peptide sequences of the human GIB PLA 2 (P04054), honeybee venom GIII PLA 2 (P00630), human GXIIA PLA 2 (Q9BZM1), O. sativa GXIB PLA 2 (Q9XG81) and $S$. violaceoruber PLA2 (Q6UV28). In addition, $\mathrm{PLA}_{2}$ and $\mathrm{PLA}_{2}$-like protein sequences were identified in the Microbial and Eukaryotic Genome database (http:// www.ncbi.nlm.nih.gov/genome) following a similar strategy. Searches were also performed on nucleotide database data and covered all completed genomes in the NCBI genome database (1359 bacterial, 79 archaeal and 231 eukaryotic genomes; October 2010 release), and also available EST data using the tBLASTn and sequence matches with an e-value of $<10$ were retrieved and their sequence analysed. The deduced protein sequences were obtained using the BCM Search Launcher (http://searchlauncher.bcm.tmc.edu/
seq-util/Options/sixframe.html) and compared with available homologue data.

\section{In silico sequence annotations}

The conserved domains of $\mathrm{SPLA}_{2}$ were identified using the NCBI Conserved Domains Database CDD-27036 PSSMs (http://www.ncbi.nlm.nih.gov/cdd) annotation by using the sequences identified in this study as queries. The result includes an alignment between the query and the search model consensus sequence, the expected-value for the alignment, the identity (name) of the conserved domain and the location of the conserved domain in the query sequence [25]. Histidine active-site and aspartic acid active-site protein motifs were identified based on the PROSITE database (http://au.expasy.org/prosite) pattern annotation. The localization of disulfide bonds was retrieved from the Swiss-Prot database and from published data.

\section{Sequence comparisons and phylogenetic analysis}

Pairwise and multiple protein sequence alignments were carried out using the ClustalW2 program [62] available from EBI (http://www.ebi.ac.uk/Tools/msa/clustalw2) and the default parameters. The percentage of sequence similarities (based on the observed substitutions of one amino acid for another in homologous proteins) and identities between the $\mathrm{sPLA}_{2} \mathrm{~S}$ were calculated based upon protein alignments using the GeneDoc interface (http:// www.psc.edu/biomed/genedoc). Phylogenetic analysis of the conserved domain sequences of bacterial, fungal and metazoan $\mathrm{PLA}_{2} \mathrm{~S}$ was performed using 53 taxa representatives. The protein alignment produced was submitted to PROTTEST analysis (http://darwin.uvigo.es/software/prottest.html) to select the best model of protein evolution that fits the data set [63]. Phylogenetic analyses were conducted using the NJ [64] and ML methods, and reliability for internal branching was assessed using the bootstrap method [65]. NJ analysis was performed using MEGA4 programme [66] and the p-distance amino acid model with 1000 bootstrap replicates. All positions containing alignment gaps and missing data were eliminated (pairwise deletion option) and a total of 215 positions were analyzed in the final data set. The ML tree (PHyML, v3.0 aLRT) [67] was constructed in Phylogeny.fr web interface (http://phylogeny.lirmm.fr/phylo_cgi/index.cgi). The WAG substitution model was selected assuming an estimated proportion of invariant sites (of 0.167) and four gamma-distributed rate categories to account for rate heterogeneity across sites. The gamma shape parameter was estimated directly from the data $(\gamma=1.804)$ and analysis was performed using 100 bootstrap replicates. Graphical representation and edition of the phylogenetic tree were performed with TREEDYN (v198.3, http://www.treedyn.org). 
Both methods produced similar tree topologies and the NJ bootstrap consensus tree was selected and taxa clades with support values $<50 \%$ collapsed.

\section{Acknowledgements}

The authors thank Deborah Power for critical reading of the manuscript and anonymous referees for valuable suggestions. Supported by the Research Fund of Turku University Hospital and the Portuguese National Science Foundation (FCT)/CCMAR pluriannual grant.

\section{References}

1 Schaloske RH \& Dennis EA (2006) The phospholipase $\mathrm{A}_{2}$ superfamily and its numbering system. Biochim Biophys Acta 1761, 1246-1259.

2 Six DA \& Dennis EA (2000) The expanding superfamily of phospholipase $\mathrm{A}_{2}$ enzymes: classificiation and characterization. Biochim Biophys Acta 1488, 1-19.

3 Murakami M, Taketomi Y, Girard C, Yamamoto K \& Lambeau G (2010) Review. Emerging roles of secreted phospholipase A2 enzymes: lessons from transgenic and knockout mice. Biochimie 92, 561-582.

4 Murakami M, Taketomi Y, Miki Y, Sato H, Hirabayashi T \& Yamamoto K (2011) Recent progress in phospholipase $\mathrm{A}_{2}$ research: from cells to animals to humans. Prog Lipid Res 50, 152-192.

5 Nevalainen TJ, Haapamäki MM \& Grönroos JM (2000) Roles of secretory phospholipases $A_{2}$ in inflammatory diseases and trauma. Biochim Biophys Acta 1488, 83-90.

6 Nevalainen TJ, Graham GG \& Scott KF (2008) Antibacterial actions of secreted phospholipases $\mathrm{A}_{2}$ : review. Biochim Biophys Acta 1781, 1-9.

7 Birts CN, Barton CH \& Wilton DC (2010) Catalytic and non-catalytic functions of human IIA phospholipase $\mathrm{A}_{2}$. Trends Biochem Sci 35, 28-35.

8 Valentin E \& Lambeau G (2000) Increasing diversity of secreted phospholipases $\mathrm{A}_{2}$ and their receptors and binding proteins. Biochim Biophys Acta 1488, 59-70.

9 Dijkstra BW, Kalk KH, Hol WG \& Drenth J (1981) Structure of bovine pancreatic phospholipase $\mathrm{A}_{2}$ at 1.7 A resolution. $J$ Mol Biol 147, 97-123.

10 Brunie S, Bolin J, Gewirth D \& Sigler PB (1985) The refined crystal structure of dimeric phospholipase $\mathrm{A}_{2}$ at 2.5 A. Access to a shielded catalytic center. J Biol Chem 260, 9742-9749.

11 White SP, Scott DL, Otwinowski Z, Gelb MH \& Sigler PB (1990) Crystal structure of cobra-venom phospholipase $\mathrm{A}_{2}$ in a complex with a transition-state analogue. Science 250, 1560-1563.

12 Wery JP, Schewitz RW, Clawson DK, Bobbitt JL, Dow ER, Gamboa G, Goodson T Jr, Hermann RB, Kramer
RM, McClure DB et al. (1991) Structure of recombinant human rheumatoid arthritic synovial fluid phospholipase $\mathrm{A}_{2}$ at 2.2 A resolution. Nature 352, 79-82.

13 Steiner RA, Rozeboom HJ, de Vries A, Kalk KH, Murshudov GN, Wilson KS \& Dijkstra BW (2001) $\mathrm{X}$-ray structure of bovine pancreatic phospholipase $\mathrm{A}_{2}$ at atomic resolution. Acta Crystallogr D Biol Crystallogr 57, 516-526.

14 Renetseder R, Brunie S, Dijkstra BW, Drenth J \& Sigler PB (1985) A comparison of the crystal structures of phospholipases $\mathrm{A}_{2}$ from bovine pancreas and Crotalus atrox venom. J Biol Chem 260, 11627-11634.

15 Guy J, Ståhl U \& Lindqvist Y (2009) Crystal structure of a class XIB phospholipase $\mathrm{A}_{2}$ : rice (Oryza sativa) isoform-2 $\mathrm{PLA}_{2}$ and an octanoate complex. $J$ Biol Chem 284, 19371-19379.

16 Matoba Y, Katsube Y \& Sugiyama M (2002) The crystal structure of prokaryotic phospholipase $\mathrm{A}_{2} . \mathrm{J}$ Biol Chem 277, 20059-20069.

17 Scott DL, Otwinowski Z, Gelb MH \& Sigler PB (1990) Crystal structure of bee venom phospholipase $\mathrm{A}_{2}$ in a complex with a transition-state analogue. Science $\mathbf{2 5 0}$, 1563-1566.

18 Hulo N, Bairoch A, Bulliard V, Cerutti L, Cuche B, De Castro E, Lachaize C, Langendijk-Genevaux PS \& Sigrist CJA (2008) The 20 years of PROSITE. Nucleic Acid Res 36, D245-D249.

19 Talvinen KA \& Nevalainen TJ (2002) Cloning of a novel phospholipase $\mathrm{A}_{2}$ from the cnidarian Adamsia carciniopados. Comp Biochem Physiol B Biochem Mol Biol 132, 571-578.

20 Razpotnik A, Križaj I, Šribar J, Kordiš D, Maček P, Frangež R, Kem WR \& Turk T (2010) A new phospholipase A2 isolated from the sea anemone Urticina crassicornis - its primary structure and phylogenetic classification. FEBS J 277, 2641-2653.

21 Romero L, Marcussi S, Marchi-Salvador DP, Silva FP Jr, Fuly AL, Stábeli RG, da Silva SL, Gonzáles J, del Monte A \& Soares AM (2010) Enzymatic and structural characterization of a basic phospholipase $\mathrm{A}_{2}$ from the sea anemone Condylactis gigantea. Biochimie 92, 1063-1071.

22 Davidson FF \& Dennis EA (1990) Evolutionary relationships and implications for the regulation for phospholipase $\mathrm{A}_{2}$ from snake venom to human secreted forms. J Mol Evol 31, 228-238.

23 Dennis EA (1994) Diversity of group types, regulation, and function of phospholipase $\mathrm{A}_{2}$. J Biol Chem $\mathbf{2 6 9}$, 13057-13060.

24 Finn RD, Tate J, Mistry J, Coggill PC, Sammut SJ, Hotz HR, Ceric G, Forslund K, Eddy SR, Sonnhammer ELL et al. (2008) The pfam protein families database. Nucleic Acid Res 36, D281-D288. 
25 Marchler-Bauer A, Lu S, Anderson JB, Chitsaz F, Derbyshire MK, DeWeese-Scott C, Fong JH, Geer LY, Geer RC, Gonzales NR et al. (2010) CDD: a Conserved Domain Database for the functional annotation of proteins. Nucleic Acid Res 39, D225-D229.

26 Beres SB, Sylva GL, Barbian KD, Lei B, Hoff JS, Mammarella ND, Liu MY, Smooth JC, Porcella SF, Parkins LD et al. (2002) Genome sequence of a serotype M3 strain of group A Streptococcus: phageencoded toxins, the high-virulence phenotype, and clone emergence. PNAS 99, 10078-10083.

27 Ståhl U, Lee M, Sjödahl S, Archer D, Cellini F, Ek B, Iannacone R, MacKenzie D, Semeraro L, Tramontano E et al. (1999) Plant low-molecular-weight phospholipase $\mathrm{A}_{2} \mathrm{~s}\left(\mathrm{PLA}_{2} \mathrm{~s}\right)$ are structurally related to the animal secretory $\mathrm{PLA}_{2} \mathrm{~S}$ and are present as a family of isoforms in rice (Oryza sativa). Plant Mol Biol 41, 481-490.

28 Nevalainen TJ (2008) Phospholipase $A_{2}$ in the genome of Nematostella vectensis. Comp Biochem Physiol D Genom Proteom 3, 226-233.

29 Pote KG, Hauer CR III, Michel H, Shabanovitz J, Hunt DF \& Kretsinger RH (1993) Otoconin-22, the major protein aragonitic frog otoconia, is homolog of phospholipase $\mathrm{A}_{2}$. Biochemistry 32, 5017-5024.

30 Valentin E, Ghomashchi F, Gelb MH, Lazdunski M \& Lambeau G (2000) Novel human secreted phospholipase $\mathrm{A}_{2}$ with homology to the group III bee venom enzyme. J Biol Chem 275, 7492-7496.

31 Sugiyama M, Ohtani K, Izuhara M, Koike T, Suzuki K, Imamura S \& Misaki H (2002) A novel prokaryotoc phospholipase $\mathrm{A}_{2}$. Characterization, gene cloning, and solution structure. $J$ Biol Chem 277, 2005120058.

32 Soragni E, Bolchi A, Balestrni R, Gambaretto C, Percudani R, Bonfante P \& Ottonello S (2001) A nutritientregulated, dual localization phospholipase $A_{2}$ in the symbiotic fungus Tuber borchii. EMBO J 20, 5079-5090.

33 Meng X, Chang Y, Qui X \& Wang X (2010) Generation and analysis of expressed sequence tags from adductor muscle of Japanese scallop Mizuhopecten yessoensis. Comp Biochem Physiol Part D Genomics Proteomics 5, 288-294.

34 McIntosh JM, Ghomashchi F, Gelb MH, Dooley DJ, Stoehr SJ, Giordani AB, Naisbitt SR \& Olivera BM (1995) Conodipine-M, a novel phospholipase $A_{2}$ isolated from the venom of the marine snail Conus magus. $J$ Biol Chem 270, 3518-3526.

35 Gelb MH, Valentin E, Ghomashchi F, Lazdunski M \& Lambeau G (2000) Cloning and recombinant expression of a structurally novel human secreted phospholipase A 2. J Biol Chem 275, 39823-39826.

36 Rouault M, Bollinger JG, Lazdunski M, Gelb MH \& Lambeau G (2003) Novel mammalian group XII secreted phospholipase $\mathrm{A}_{2}$ lacking enzymatic activity. Biochemistry 42, 11494-11503.

37 Bókay A (1877) Ueber die Verdaulichkeit des Nucleins und Lecithins. Ztschr Physiol Chem 1, 157-164.

38 Burke JE \& Dennis EA (2009) Phospholipase A2 biochemistry. Cardiovasc Drug Ther 23, 49.

39 Tan PTJ, Khan MA \& Brusic V (2003) Bioinformatics for venom and toxin sciences. Brief Bioinform 4, 53-62.

40 Lynch VJ (2007) Inventing an arsenal: adaptive evolution and neofunctionalization of snake venom phospholipase A2 genes. BMC Evol Biol 7, 2.

41 Heinrikson RL, Krueger ET \& Keim PS (1977) Amino acid sequence of phospholipase $\mathrm{A}_{2}$-alpha from the venom of Crotalus adamanteus. A new classification of phospholipases A2 based on structural determinants. J Biol Chem 252, 4913-4921.

42 Wang Y, Kowalski PE, Thalman I, Ornitz DM, Mager DL \& Thalmann L (1998) Otoconin-90, the mammalian otoconial matrix protein, contains two domains of homology to secretoty phospholipase $\mathrm{A}_{2}$. Proc Natl Acad Sci USA 95, 15345-15350.

43 Zádori Z, Szelei J, Lacoste MC, Li Y, Gariépy S, Raymond P, Allaire M, Nabi IR \& Tijssen P (2001) A viral phospholipase $A_{2}$ is required for parvovirus infectivity. Dev Cell 1, 291-302.

44 Woese CR, Kandler O \& Wheelis ML (1990) Towards a natural system of organisms: proposal for the domains Archaea, Bacteria, and Eukarya. PNAS 87, 4576-4579.

45 Hemmi H, Shibuya K, Takahashi Y, Nakayama T \& Nishino T (2004) (S)-2,3-Di-O-geranylgeranylglyceryl phosphate synthase from the thermoacidophilic archeon Sulfobolus solfataricus. Molecular cloning and characterization of a membrane-intrinsic prenyltransferase involved in the biosynthesis of archaeal ether-linked membrane lipids. J Biol Chem 279, 5019750202.

46 Cavalier-Smith T (2009) Review. Predation and eukaryote cell origins: a coevolutionary perspective. Int $J$ Biochem Cell Biol 41, 307-322.

47 Nakashima K, Ogawa T, Oda N, Shimohigashi Y, Hattori M, Sakaki Y, Kihara H \& Ohno M (1994) Darwinian evolution of Trimeresurus flavoviridis venom gland phospholipase $\mathrm{A}_{2}$ isozymes. Pure Appl Chem 66, 715-720.

48 Kini RM \& Chan YM (1999) Accelerated evolution and molecular surface of venom phospholipase $\mathrm{A}_{2}$ enzymes. J Mol Evol 48, 125-132.

49 Fry BG (2005) From genome to "venome": molecular origin and evolution of the snake venom proteome inferred from phylogenetic analysis of toxin sequences and related body proteins. Genome Res 15, 403-420.

50 Golik M, Cohen-Zinder M, Loor JJ, Drackley JK, Band MR, Lewin HA, Weller JI, Ron M \& Seroussi E (2006) Accelerated expansion of group IID-like 
phospholipase $\mathrm{A}_{2}$ genes in Bos taurus. Genomics 87 , 527-533.

51 Tischfield JA (1997) A reassessment of the low molecular weight phospholipase $\mathrm{A}_{2}$ gene family in mammals. J Biol Chem 272, 17247-17250.

52 Koduri RS, Grönroos JO, Laine VJO, Le Calvez C, Lambeau G, Nevalainen TJ \& Gelb MH (2002) Bactericidal properties of human and murine groups I, II, V, $\mathrm{X}$, and XII secreted phospholipases $\mathrm{A}_{2} . \mathrm{J}$ Biol Chem 277, 5849-5857.

53 Chen JY, Oliveri P, Gao F, Dornbos SQ, Li CW, Bottjer DJ \& Davidson EH (2002) Precambrian animal life: probable developmental and adult cnidarian forms from Southwest China. Dev Biol 248, 182-196.

54 Wood RA, Grotzinger JP \& Dickson JA (2002) Proterozoic modular biomineralized metazoan from the Nama group, Namibia. Science 296, 2383-3286.

55 Armugam A, Gong NL, Li XJ, Siew PY, Chai SC, Nair R \& Jeyaseelan K (2004) Group IB phospholipase $A_{2}$ from Pseudonaja textilis. Arch Biochem Biophys 421, 10-20.

56 Putnam NH, Srivastava M, Hellsten U, Dirks B, Chapman J, Salamov A, Terry A, Shapiro H, Lindquist E, Kapitonov VV et al. (2007) Sea anemone genome reveals ancestral eumetazoan gene repertoire and genomic organization. Science 317, 86-94.

57 Ho I, Arm JP, Bingham CO, Choi A, Austen KF \& Glimcher LH (2001) A novel group of phospholipase $\mathrm{A}_{2} \mathrm{~s}$ preferentially expressed in type 2 helper $\mathrm{T}$ cells. $J$ Biol Chem 276, 18321-18326.

58 Guan M, Qu L, Tan W, Chen L \& Wong C (2011) Hepatocyte nuclear factor-4 alpha regulates liver triglyceride metabolism in part through secreted phospholipase $\mathrm{A}_{2}$ GXIIB. Hepatology 53, 458-466.

59 Crow KC \& Wagner GP (2006) What is the role of genome duplication in the evolution of complexity and diversity? Mol Biol Evol 23, 887-892.

60 Páramo L, Lomonte B, Pizarro-Cerdá J, Bengoechea JA, Gorvel JP \& Moreno P (1998) Bactericidal activity of Lys-49 and Asp-49 myotoxic phospholipase $\mathrm{A}_{2}$ from Bothrops asper snake venom: synthetic Lys49 myotoxin II-(115-129)-peptide identifies its bactericidal region. Eur J Biochem 253, 452-461.
61 Altschul SF, Madden TL, Schäffer AA, Zhang J, Zhang Z, Miller W \& Lipman DJ (1997) Gapped BLAST and PSI-BLAST: a new generation of protein database search programs. Nucleic Acids Res 25, 33893402.

62 Larkin MA, Blackshields G, Brown NP, Chenna R, McGettigan PA, McWilliam H, Valentin F, Wallace IM, Wilm A, Lopez R et al. (2007) Clustal W and Clustal X version 2.0. Bioinformatics 23, 2947-2948.

63 Abascal F, Zardoya R \& Posada D (2005) ProtTest: selection of best-fit models of protein evolution.

Bioinformatics 21, 2104-2105.

64 Saitou N \& Nei M (1987) The neighbor-joining method: a new method for reconstructing phylogenetic trees. Mol Biol Evol 4, 406-425.

65 Felsenstein J (1985) Confidence limits on phylogenies: an approach using the bootstrap. Evolution 39, 783791.

66 Tamura K, Dudley J, Nei M \& Kumar S (2007) MEGA4: Molecular Evolutionary Genetics Analysis (MEGA) software version 4.0. Mol Biol Evol 24, 1596-1599.

67 Guindon S \& Gascuel O (2003) A simple, fast, and accurate algorithm to estimate large phylogenies by maximum likelihood. Syst Biol 52, 696-704.

\section{Supporting information}

The following supplementary material is available:

Fig. S1. Alignment of the conserved domain pfam06951 sequences of 20 GXIIA PLA 2 s.

Table S1. Conserved domains of 333 prokaryotic and eukaryotic secreted phospholipases $\mathrm{A}_{2}$.

This supplementary material can be found in the online version of this article.

Please note: As a service to our authors and readers, this journal provides supporting information supplied by the authors. Such materials are peer-reviewed and may be re-organized for online delivery, but are not copy-edited or typeset. Technical support issues arising from supporting information (other than missing files) should be addressed to the authors. 